\title{
MAS AFINAL, O QUE É MESMO UNIVERSAL?: SOBRE O ENTRE-LUGAR DA LITERATURA (DA CULTURA) DA AMAZÔNIA EM TEMPOS DE CULTURAS HÍBRIDAS
}

Emídio Júnior Santos BAHIA ${ }^{1}$ emidiobahia@hotmail.com

Resumo: O objeto desse trabalho é discutir a dicotomia universal/local na literatura (na cultura) da Amazônia, constitutiva de um processo amplo de miscigenação que dá forma e vida aos processos simbólicos, ratificando a ideia de que a cultura amazônica é uma cultura universal por ser híbrida, mesmo sendo marginalizada. O objetivo desse trabalho é analisar sob a ótica de Néstor Canclini, Goethe, Faustino dentre outros, que a literatura (cultura) da Amazônia apresenta uma sistemática de intercâmbio cultural. A metodologia utilizada para a compreensão é o método comparativo-descritivo. Os resultados mostram-nos que a miscigenação resultante da formação social amazônica, que transita entre uma cultura moderna e uma tradicional, reflete-se na produção simbólica da região, que as produções que propõem um intercâmbio cultural podem ser consideradas, segundo a ótica de Goethe, universais, mas que muito do considerado universal não mais é do que imitação de outros processos simbólicos, superando-os ou diluindo-os.

Palavras-chave: Literatura (cultura) da Amazônia. Universal-Local. Culturas híbridas. Cultura de Margem.

Abstract: The object of this work is discuss the universal / local dichotomy in the literature (culture) of the Amazon, constitutive of a large miscegenation process which gives life and form to the symbolic process, reaffirming the idea that the Amazonian culture is a universal culture for being hybrid, even though marginalized. The objective of this work is to analyze under the scope of Nestor Canclini, Goethe, and Faustino among others, that the literature (culture) of Amazon presents a systematics of cultural interchange. The methodology chosen in order to comprehend is the descriptive-comparative method. The results show us that the miscegenation resulting from the Amazonian social

\footnotetext{
${ }^{1}$ Graduado em Letras/Língua Portuguesa, na Universidade do Estado do Pará.
} 
formation, which transits between a modern and a traditional culture, reflects on the symbolic production of the region; and that the productions that propose a cultural interchange can be considered, according to Goethe: Universal. And much of what is considered universal, is not more than imitation of other symbolic processes, overcoming or diluting them.

Keywords: Literature (culture) of the Amazon. Universal-Local. Hybrid Cultures. Marginal Culture.

\section{Introdução}

Esse artigo tem por finalidade expor algumas considerações teóricas sobre a dicotomia universal e local na literatura (na cultura) da Amazônia, resultante, como será exposto, de um processo de miscigenação cultural amplo, que dá forma e vida aos processos simbólicos, ratificando a ideia de que a cultura amazônica é uma cultura universal por ser híbrida, mesmo sendo marginalizada (nesse caso considera-se esse marginalizado como cultura da margem, excluída), e que a dicotomia universal e local não existe, de fato, no eixo da cultura assim como vem sendo transmitido boca a boca, e sim num eixo de pensamento totalmente diferente daquilo que se compreende como sistema universal de cultura, logo, de arte.

O método de análise utilizado na exposição é o comparativodescritivo, fazendo um paralelo com as teorias elencadas para a fundamentação teórica aqui abordada e a ratificação ou não dos conceitos. Para tanto, foram utilizados, como corpo teórico, autores diversos que tratam do tema Universalismo, como Goethe, no campo da literatura, e Silviano Santiago, no eixo das ciências sociais, além de outros teóricos que abordam conceitos relevantes e que ratificam ideias para o desenvolvimento desse modo de pensar a cultura amazônica aqui exposto, como: a interpretação de Kestler (2008), para a ideia de universalismo exposta por Goethe, a qual versa o universal como intercâmbio cultural; os conceitos de imitação e diluição utilizados por Faustino (2003), ratificando e ideia de que não existe nada unívoco e sim, múltiplo; e as considerações teóricas sobre culturas híbridas de Néstor Canclini.

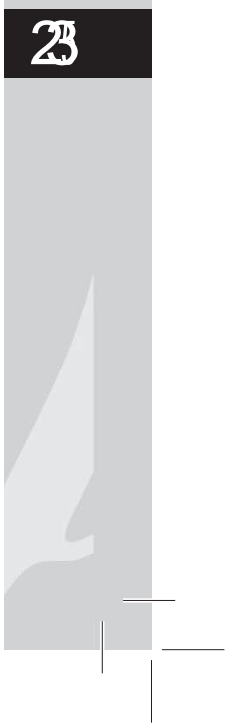




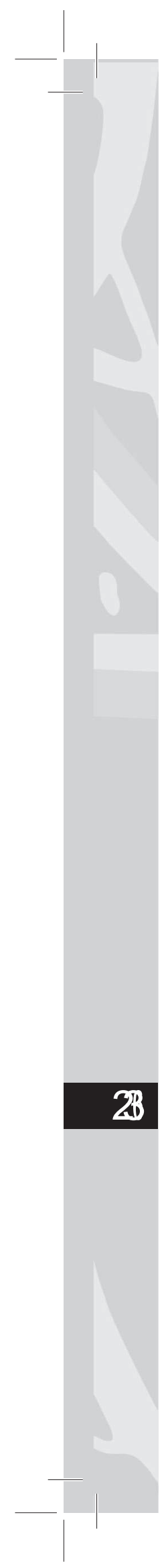

A discussão sobre o particular (local) e o universal em lugares que não estão ligados diretamente àquilo que se convencionou chamar centro cultural $^{2}$ (como acontece no Brasil no eixo Sul-Sudeste, onde tudo aquilo que está à margem não é considerado cultura nacional muito mais por razões político-ideológicas do que estéticas), ainda é bastante frequente. A busca do entre-lugar ${ }^{3}$ universal/local provocou uma discussão acalorada em Belém-PA, quando nos referimos à nomenclatura dada à literatura produzida no Pará.

Em artigo publicado pelo Prof. Paulo Nunes, noblog: escritoresap. blogspot.com, sob o título Literatura Paraense Existe?! Nunes considera que a expressão Literatura Paraense: "além de ser acanhada demais, fere a universalidade, princípio básico a qualquer manifestação que se deseje artística". (NUNES, 2008, p. 1). E segue argumentando que a aceitação da denominação literatura paraense para as manifestações literárias produzidas no Pará significa "cairmos numa armadilha fácil, montada por aqueles que tentam nos perpetuar como frutos de uma cultura exótica, regional, incapaz de difundir sentimentos universais" (Idem). Logo, a denominação Literatura Paraense deve ser substituída pela adjetivação-pátria literatura brasileira de expressão amazônica, em virtude da não superfragmentação de um processo cultural bem mais amplo, o nacional.

Já Edilson Pantoja, em seu artigo Não Existe Uma Literatura Paraense?!4, em contraposição ao pensamento de Nunes, afirma que a

\footnotetext{
${ }^{2}$ Define-se centro cultural aquilo que se compreende como cultura do centro, com poderes político-ideológicos numa dada cultura, e se autointitulando cultura nacional, em contraposição à cultura de margem, "excluída", periférica.

${ }^{3}$ Entre-lugar é termo utilizado por (FERNANDES, 2005) para denominação de "entremeio", "entremeado" que são, segundo o autor, expressões utilizadas na linguagem coloquial dos "caboclos" e "ribeirinhos" da Amazônia paraense para se referirem a alguma coisa misturada. Como o encontro das águas entre o rio Negro e o Solimões, um com águas claras e outro com águas escuras; O entre-lugar é justamente a linha híbrida que divide e ao mesmo tempo mistura as águas dos dois rios, como uma penumbra.

${ }^{4}$ Cf. texto publicado originalmente em site, fevereiro de 2003, mas foi removido. Postado por João Jorge Pereira dos Reis. Disponível em: http://joaojorgereis. blogspot.com/2011/08/nao-existe-uma-literatura-paraense.html Acesso: 20/05/2012
} 
troca de designação para literatura brasileira de expressão amazônica não é mais que uma mudança de nomenclatura que não oblitera o termo Literatura Paraense, mas o substitui por outro termo de igual valor. E que não se pode "em nome de um desejo de universalização, suprimir o regional" (PANTOJA, 2003), afirmando que sem o local (o particular) não existiria o universal, e nem o nacional sem o regional.

\section{Mas o que é mesmo Universal?}

Determinemos aqui duas ideias sobre aquilo que é considerado universal. Uma no conceito da própria área da literatura advindo de Goethe, segundo consta, o primeiro a usar esse termo nos estudos literários; e outra fundada na exposição do teórico Silviano Santiago, também da área da literatura, mas com um viés voltado para a área das ciências sociais. Segundo Goethe em trecho de uma de suas cartas denominado Poesia e Universalismo ${ }^{5}$, ele define universal da seguinte forma:

Vejo cada vez mais [...] que a poesia é um bem comum da humanidade, um bem que aparece por todo lugar e em todas as épocas, em centenas e centenas de pessoas. [...] A bem verdade, se nós, alemães, não olharmos para além do nosso ambiente estreito, sucumbimos com certa facilidade à arrogância tola. Por esse motivo, gosto de acompanhar outras nações; $e$ aconselho a todos a fazer o mesmo. Nestes tempos, a literatura nacional não quer dizer muito, a hora é da literatura do mundo, e cada um deveria contribuir para o seu desenvolvimento. Estimar o que vem do estrangeiro, contudo, não nos deveria levar à fixação em coisas particulares, considerando-as modelo. Não convém pensar que a China é exemplar, ou a

\footnotetext{
${ }^{5}$ ECKERMANN, Johann Peter. Gesprächemit Goethe in den letzten Jahren seines Lebens. In: SOUZA, Roberto Acízelo de. (Org.). Poesia e universalismo: uma ideia moderna de literatura - textos seminais para os estudos literários (1688-1922). Chapecó Argos, 2011, p. 132.
}

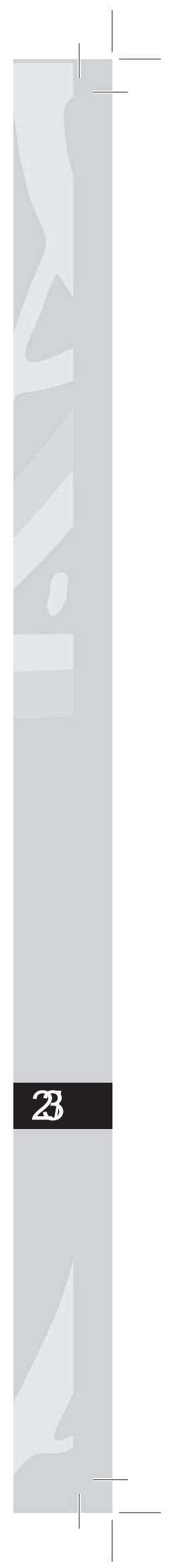


Sérvia, Calderón, os Nilbelungen. Em vez disso, se desejarmos o modelo, temos de voltar aos gregos, cuja obra sempre reproduziram a beleza humana. Tudo o mais devemos contemplar apenas do ponto de vista histórico, aproveitando tudo que há de bom, sempre na medida do possível.

A ideia de Goethe de universal está ligada à observação do estrangeiro, da cultura além da nacional, no entanto, não tomando as coisas particulares. E se quisermos utilizar um modelo, devemos voltar aos gregos, cujas obras sempre reproduziram a beleza humana. Nesse sentido, Goethe se fixa não em um particular, e sim em um modelo que reproduza a beleza, para a utilização como molde. Logo, a ideia exposta propõe uma busca da beleza (no sentido estético do termo), aproveitando tudo, na medida do possível.

Afinal, o que é ser universal? Segundo Kestler (2008), no artigo: "O conceito de literatura universal em Goethe", é possível compreender que a ideia de Goethe está mais ligada ao processo de comunicação e àquilo que há de comum entre as diferenças culturais, aquilo que ele denomina:Weltliteratur (Literatura Mundial).

Depreende-se de suas reflexões expostas em cartas, conversas e resenhas que Goethe entende Weltliteratur não no sentido de um cânone literário de obras exemplares e muito menos no sentido de um sumário quantitativo sempre crescente de obras literárias de todas as épocas e lugares. Goethe denomina de Weltiteratur o que atualmente chamamos de intercâmbio e comunicação intercultural, nos quais se manifestaria o que há em comum entre as diferentes culturas, sem que se apague a individualidade que se baseia em diferenças nacionais. No sentido prático, Weltliteratur se refere à tarefa dos escritores e poetas, que devem fomentar o intercâmbio intelectual através de traduções, resenhas, discussões e encontros pessoais. A ideia da universalidade da poesia combina-se, no conceito goetheano de Weltliteratur, à necessidade da prática da tolerância entre os povos, 
da aceitação das diferenças culturais e da ênfase no universalmente humano. [...] Não se baseia em ideias de homogeneização cultural e muito menos em noções particularistas, sectárias, de uma suposta superioridade cultural de determinados povos ou em ideais patrióticos. Pelo contrário. Para Goethe, já desde a época do assim chamado Classicismo de Weimar, ou melhor, de sua coalizão estética com Schiller, a partir de 1794 e até a morte deste em 1805, não se tratava de valorizar o estritamente nacional em detrimento do universal. (KESTLER, 2008, p.).

Nesse sentido, a ideia de Weltliteratur, segundo Kestler (2008), não está calcada em um paradigma estético de homogeneização e de noções particularistas de segregação, e sim de tolerância, intercâmbio e comunicação intercultural, buscado no que há de comum nas diferenças culturais; que o intercâmbio intelectual, por meio das traduções, resenhas deve ser estimulado para o viés de uma literatura do mundo, universal, mas que também observe o particular, ao mesmo tempo não se restringe somente a esse, e não acatando medidas de superioridade e homogeneização de cultura(s).

Já no campo das ciências sociais, Silviano Santiago discute a denominação universalidade como um jogo do colonizador com o intuito de difundir a história da Europa como universal e a difusão de uma uniformização ocidental do mundo, tornando-nos reféns desse processo. Segundo ele:

A universalidade ou bem é um jogo do colonizador, em que se consegue pouco a pouco a uniformização ocidental do mundo, a sua totalização, através da imposição da história europeia como Historia universal, ou bem é um jogo diferencial em que as culturas, mesmo as em situação econômica inferior, se exercitam dentro de um espaço maior, para que se acentuem os choques das ações de dominação $e$ as reações dos dominados (SANTIAGO, 1982, $p$. 23-24).

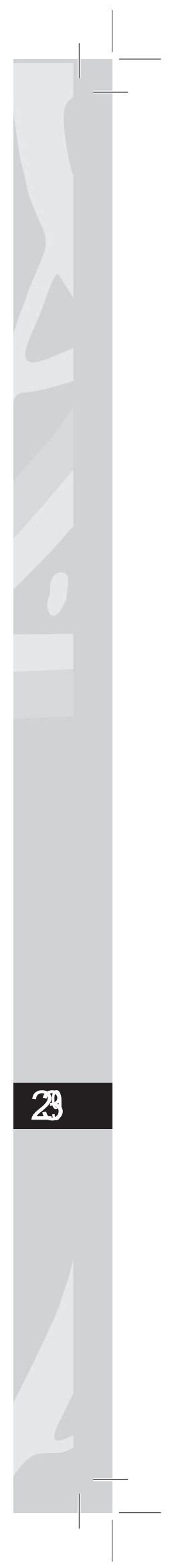




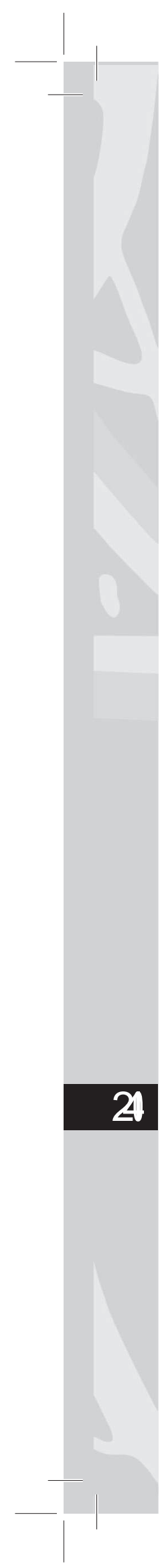

Nesse sentido, a universalidade seria um bem, criado para a dominação cultural de um espaço maior (o global) de sistemas, que, numa tentativa de afirmação identitária, puramente etnocêntrica ${ }^{6}$, impõe, por meio da ratificação da história da Europa como uma história universal, uma hegemonia cultural e uma tentativa de homogeneização do processo cultural, instituindo um modelo de vida e de cultura amplamente difundido na hipermídia nesse século e pelos jornais desde os séculos XVIII e XIX, demonstrando o importante papel da mídia como propagadora desse sistema ideológico de uniformização da cultura ocidental, principalmente na América.

Logo, no sentido aqui exposto, corroborado pelo conceito de Goethe, ser universal é ser híbrido. É ser a mistura, o entremeio, de sistemas simbólicos diferentes. É a não restrição do olhar no local, no particular, e sim, tomar "o local e o universal", a literatura (a cultura) regional e a do mundo em um sentido em que ambas convivam em harmonia na busca por uma beleza; não havendo superposição ou imposição de sistemas simbólicos, tornando outros sistemas reféns de processos colonizatórios e midiáticos que professam ideologias de homogeneização em favor de um sistema "ocidental" de cultura e de vida, que desconsideram particularidades mais por questões político-ideológicas do que estéticas, marginalizando culturas em nome de um etnocentrismo estéril e uniformizador.

\section{Sobre a hibridação cultural e a universalização da cultura}

Existe cultura pura? Durante muitos anos, os nacionalsocialistas germânicos propagaram aos quatro ventos a ideologia da

\footnotetext{
6 "A busca identitária, inevitável durante os períodos de crise, corre o risco, contudo, de transformar-se em etnocentrismo, isto é, em 'erigir', de maneira indevida, os valores próprios da sociedade à qual se pertence, em valores universais" (TODOROV apud BERND, 2003, p. 17).
} 
raça pura - a ariana de ascendência germânica -, a qual seria o berço de uma cultura superior. Justificativa como se sabe para o massacre do qual foram vítimas centenas de judeus. Esse etnocentrismo na cultura é algo que muito se discutiu e se discute. Não seria o Sentimento Ocidental um etnocentrismo? O que seria a cultura ocidental? Seria realmente uma homogênea cultura de Atenas, Paris, Londres, New York, Ciudad do México, Brasília e Buenos Aires?

Sabemos que jamais houve e jamais haverá na história da humanidade uma cultura pura. O que há são as culturas de menos contato e as culturas de mais contato social, o que possibilita uma maior troca simbólica, no caso da segunda, e uma menor, no caso da primeira. No entanto, com o processo de globalização da cultura, desde meados do século XIX (com a segunda revolução industrial) até hoje, com a hipermídia, o contato entre os povos de diferentes culturas foram se estreitando e se entrelaçando. Criando uma hibridação cultural bem mais aparente do que outrora. Um exemplo é o processo de ocidentalização da cultura oriental e do médio oriente. Hoje Xangai e Pequim não são mais as burlescas cidadelas na qual ainda se utiliza como meio de transporte principal os riquixás, mas outros meios mais velozes e contemporâneos como os metrôs e os trens-bala. No cenário social contemporâneo de Tóquio, as gueixas já não produzem o mesmo papel.

O que vemos nesses países é um modo de vida quase semelhante ao modelo de vida divulgado pela mídia nesse sistema de universalização da cultura ocidental (germano-franco-britânica); e agora, no final do século XX e início do XXI, a cultura americana (estadunidense) criando um processo denominado: universalização da cultura, tentativa de homogeneização do processo cultural, que Santiago (1982) define como: "uniformização ocidental do mundo". No entanto, por maior que seja a tentativa de homogeneização, essas ainda preservam processos tradicionais, certos aspectos da cultura local.

Percebe-se, em contraposição a tentativa de homogeneização da cultura, nessas e em outras metrópoles, um modelo de vida que 


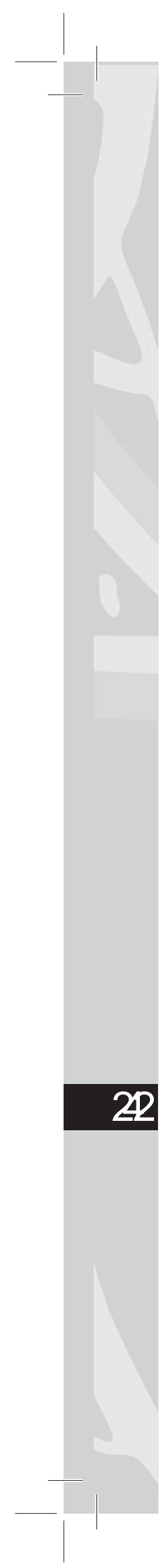

mistura tradicional e moderno, como ocorre na Índia, com o seu sistema de castas. Politicamente já extintas, mas enraizada ainda hoje no cerne da cultura local; onde as vacas circulam em meio aos automóveis modernos de fábricas europeias e aos transportes típicos, em um país emergente, com um dos maiores PIB e a democracia mais populosa do planeta. Assim como ocorre em Istambul (Turquia) e Dubai (Emirados Árabes), cidades que misturam tradição e modernidade, passadismo e modernismo, artesanato e modernização, instaurando um sistema cultural híbrido, resultado do contanto entre diferentes culturas. Como cita (BAUDELAIRE, 1998), "todo moderno tem uma tradição". Nesse caso, tradição e moderno são pares dicotômicos intrínsecos, viventes em uma relação de mutualismo contínuo.

Mas essas culturas em contato não são um fenômeno novo no cenário social da modernidade e pós-modernidade, e sim, algo que sempre houve, mas com menor intensidade. O comércio é o maior incentivador desse processo de hibridação cultural. Os Pidgins ${ }^{7}$ são exemplos desse processo. As próprias cidades também são exemplos dessa sistemática híbrida cultural. Durante a Idade Média, as grandes cidades eram inabitadas e o espaço cultural estava restrito as pequenas vilas e à vida campesina, criando um isolamento e uma miscigenação cultural menos intensa, mas ocorrente devido aos andarilhos que circulavam entre essas vilas, e também, é claro, aos comerciantes. Os jograis e menestréis são exemplos de andarilhos que transmitiam a cultura pela via oral, e por meio desse a cultura sofreu algumas transformações e hibridações. Nesse caso, não levamos em conta aquilo que se entende como um profissional "contador de histórias" dotado de certa sistematicidade do ato de contar e tão bem exemplificado por V. I Propp, em Morfologia do

\footnotetext{
7 "O inglês pidgin que se desenvolveu nos contatos comerciais entre ingleses e chineses ao longo da costa do mar da China, tomando o vocabulário emprestado do inglês e sua sintaxe ao chinês (a origem do termo pidgin seria, aliás, a deformação do termo inglês business, que indicaria bem a função social dessa forma linguística)". (CALVET, 2002. p. 42).
} 
Conto Maravilhoso, mas sim por pessoas responsáveis pelo contato cultural entre os povos europeus e difusores de processos simbólicos de origens diversas. Mas esse sistema de hibridação não detém o mesmo poder de miscigenação do que as grandes cidades, principais responsáveis por trocas simbólicas intensas e significativas na história das culturas. Miscigenando sistemas simbólicos e recriando/ reinventando culturas.

$\mathrm{Na}$ Amazônia, o isolamento resultante da vastidão territorial, da densidade da floresta e do abandono da região até antes da descoberta do látex na região (a partir da segunda metade do século XIX) institui um sistema cultural relativamente pouco miscigenado. Nesse período, a cultura amazônica estava restrita à cultura indígena, à cultura "branca" e à africana (oriunda do processo de escravidão), resultado das incursões dos colonos na região, sendo que, pela vastidão territorial desde os últimos limites do Ceará à subida do Amazonas até Castella, não havia mais do que nove povoações de brancos, sendo que, dessas, três eram vilas de donatários em extrema decadência e abandono, segundo relata d'Azevedo (1999, p. 189-190). Mas com a exploração do látex, a região rapidamente se desenvolveu, e em poucos anos Belém e Manaus, pequenas vilas ribeirinhas, esquecidas no Inferno Verde, de Alberto Rangel, transformaramse em grandes cidades, mímese de Paris e Londres, onde circulavam: bondes, companhias de teatro europeias que se apresentavam em teatros neoclássicos suntuosos, populações nordestinas, paulistas, capixabas, inglesas, dentre outras. O resultado desse processo é um sistema cultural extremamente peculiar, mistura de um sistema social ocidental, moderno (no sentido de modernização resultante do modelo de vida industrial), universalizado, e um sistema local, oriundo do modelo de vida indígena e ribeirinho, caboclo, criando um estreitamento de laços entre a Amazônia e o restante do sistema cultural brasileiro e estrangeiro. O resultado é uma cultura híbrida que mistura uma tradição oral, advinda das culturas indígena e africana, e uma cultura também de tradição escrita, ligada à cultura europeia, com a circulação de romances franceses na região por meio 
dos gabinetes de leitura, como o Grêmio Literário Português, e dos jornais diários, que publicavam variedades, de contos até romancesfolhetins.

No campo da literatura, muito daquilo que é considerado universal é apenas imitação, diluição ou influência de obras, autores e estilos. O que seria d'Os Cantos poundianos sem Homero? (o próprio Pound admite a influência); haveria a cultura brasileira como a conhecemos hoje sem as culturas portuguesa, espanhola, africana e indígena? Dalí sem Breton? (Será que Dalí faria quadros surrealistas? Teria ele não se insurgido contra seus professores passadistas da Real Academia de Belas Artes de São Fernando e tornado-se o Dalí que conhecemos?) Buñuel sem Dalí? (Teria feito o monumental Um Chien Andalou). Mário Faustino, poeta, jornalista e crítico de poesia brasileira diz o seguinte sobre a imitação e a diluição ${ }^{8}$ :

Camões lírico imitou Petrarca; Camões épico, Virgílio, que por sua vez imita Homero. Diluindo, entretanto, Camões eventualmente supera seu modelo (Petrarca: sonetos e canzoni) e quase sempre transforma-o, imprimindo outras direçôes as suas linhas de força (imitando Virgílio). Mas os imitadores de Camões, em Portugal e no Brasil, sempre foram meros diluidores, servindo apenas para enfraquecer e vulgarizar a corrente original. O caso de Bento Teixeira, com sua Prosopopéia ${ }^{9}$ é o mesmo dos portugueses Jerônimo Corte Real (Segundo cerco de Diu, 1574) e Francisco de Andrade (Primeiro cerco de Diu, 1589): Camões diluído sem vigor criador e sem competência téenica (FAUSTINO, 2003, p. 51).

\footnotetext{
${ }^{8}$ Para Faustino o conceito de diluição é imitação sem progresso em relação ao modelo original. (Cf. FAUSTINO, 2003, p.43).

${ }^{9}$ Imitação abrasileirada d'Os Lusíadas de Camões.
} 
A história da humanidade está repleta de imitadores, diluidores, Ipsis litteris ${ }^{10} \mathrm{de}$ autores que influenciaram outros etc. Por isso o sentimento de universalização da cultura está repleto de equívocos, sobretudo ideológicos. No mundo contemporâneo, não se fala mais em identidade, e sim em identidades, resultante do conflito desse sistema cultural híbrido, no qual o Ser já não se identifica totalmente com o seu espaço ou não consegue se identificar com os traços daquilo que entende como sistema simbólico, fruto da cultura local, demonstrando um sistema cultural muito mais múltiplo do que unívoco ${ }^{11}$. Por isso há a falta de identificação com o esse meio extremamente híbrido, caleidoscópico, da contemporaneidade.

\section{Literatura (cultura) da Amazônia: processos de miscigenação}

Nos termos da literatura da Amazônia, aquilo que é considerado universal é justamente aquilo que dialoga, que permeia entre o local, nas vozes literárias da região, e o universal, desde os motes, cor local, metro. Seria Dalcídio Jurandir, local? Os bucólicos personagens de Chove nos campos de Cachoeira são marajoaras, mas apresentam conflitos sociais e existenciais. Seria Eutanázio mais bucólico que Fabiano12?! Segundo Fares (1996, p. 55): "No viés de Eutanázio, o mundo era visto através das lentes do pessimismo e da amargura", assim como ocorre em Vidas Secas, com Fabiano, Werther, de Goethe, dentre outros personagens da literatura denominada universal. A cor

\footnotetext{
${ }^{10}$ Expressão latina que significa: literalmente, pelas mesmas letras.

${ }^{11}$ Utilizo-me nessa passagem do conceito de Deleuze sobre a univocidade do ser. Segundo Zourabichvili (2004, p. 58) é: "univocidade é a síntese imediata do múltiplo: o um não se diz mais do múltiplo, senão em vez de este último se subordinar ao um como ao gênero superior e comum capaz de englobá-lo. Isso significa que o um não é mais que o diferenciante das diferenças, diferença interna ou síntese disjuntiva”.

${ }^{12}$ Personagens dos romances de Dalcídio Jurandir e Graciliano Ramos, respectivamente.
}

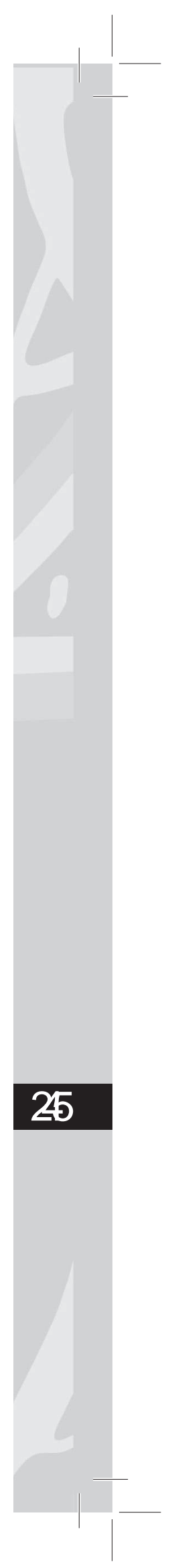




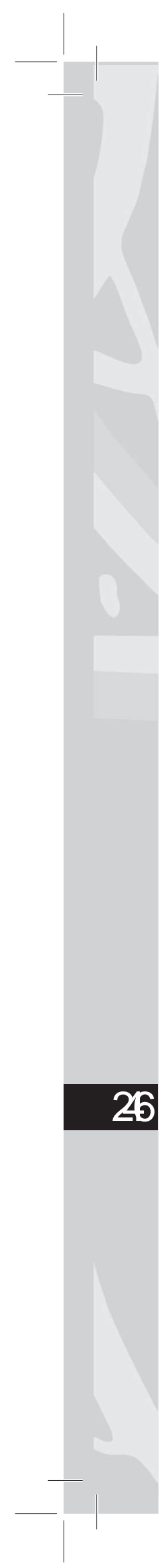

local de Dalcídio pode ser regional, mas as temáticas, o metro são universais. O romance e os problemas sociais e existenciais não são exclusividade do sistema simbólico amazônico. O que há em Dalcídio é o regional sem o regionalismo. Característica que perpassa muitos dos escritores do modernismo de 1930 na literatura brasileira, como Graciliano Ramos, Guimarães Rosa, José Lins do Rego, e ratificado pelos professores-jurados de estética (como diria Baudelaire ${ }^{13}$ ) como um modelo a ser seguido pelos escritores que enveredem por essas águas tormentosas e até profanas das literaturas consideradas locais, de margem.

Temáticas como o amor, a religião, a morte dão o tom de muitas obras poéticas consideradas universais na literatura mundial e da Amazônia. Os conflitos de amor (homo) erótico em Mário Faustino não são considerados regionalistas, não pelo seu caráter de abordar temáticas ditas universais, mas pelo seu constante diálogo com T. S. Eliot, Pound e poetas de língua inglesa aproveitando o possível na busca por uma beleza. Os conflitos religiosos e o diálogo com o anjo de Rilke feitos pelo próprio Faustino e por Paulo Plínio Abreu também não podem ser considerados regionalistas, pois seguem uma lógica de não particularização, da observação de outros sistemas simbólicos, assim como a poesia concreta, com motes filosóficos, de Max Martins, com a utilização de um sistema estético não voltado totalmente para o local.

A poesia erótica de Olga Savary também se enquadraria na ótica acima abordada. Os seus traços temáticos, a utilização microssintagmática, não particulariza a obra. Há diálogo com Decameron, de Boccaccio, com Justine, de Sade, com a erótico-poética, de Affonso Romano de Sant'Anna, confirmando que, em termos de processo de comunicação intercultural e influências, a sua poesia não poderia ser tachada de regionalista.

\footnotetext{
${ }^{13}$ BAUDELAIRE, Charles. A exposição Universal de 1855. In: A modernidade de Baudelaire. Trad. Suely Cassal. Rio de Janeiro: Paz e Terra, 1998.
} 
Os autores descritos anteriormente são aquilo que a crítica literária local e mesmo a nacional considera o mais importante (o universal) da literatura produzida no Pará. Mas e a Academia do Peixe Frito ${ }^{14}$ ? Seria possível tachá-la de regionalista, local? Bruno de Menezes, maior representante desse grupo, descreve, em Batuque ${ }^{15}$, uma Amazônia realmente intimista, enfocando para as temáticas da região, mas o que se desconhece é que a obra vai além... O batuque do negro, nas prosas poéticas de Bruno de Menezes, revela as sonoridades da região amazônica e além dela. A sonoridade de uma cultura não só amazônida, pois apresenta como referências musicais o lundum, jongo, carimbó, samba, chorinho, maxixe, quadrinha, toada, ladainha ${ }^{16}$, do batuque do tambor vindo com as naus séculos antes, com os negros escravizados, as quais estão presentes na obra de Bruno de Menezes e em outras obras da cultura nacional, e, por que não dizer, mundial. Ratificando a ideia da não observação somente do particular, pois a sonoridade descrita por Bruno, em Batuque, não são somente fruto de um sistema local, mas múltiplo, aproveitando o possível de outros sistemas.

Muito daquilo que se considera local, fruto simbólico da cultura da região, não mais é do que um híbrido com origens diversas e muitas vezes, desconhecidas. Néstor Canclini (2008) afirma que muitas das obras da arte e da literatura latino-americanas são realizações de fora do nosso continente, no entanto, são interpretadas como paradigmas da nossa identidade.

\footnotetext{
14 "A Academia do Peixe Frito é marca de resistência de uma geração de escritores paraenses, conhecida também como "geração do peixe frito", que se baseou no costume do paraense de se alimentar de peixe e gostar muito de comer peixe frito. Um grupo de escritores - Bruno de Menezes, Jacques Flores - Rodrigues Pinajé , De Campos Ribeiro - se reunia no mercado, no Ver-o-Peso, no final da manhã, para bebericar e tirar gosto com peixe-frito". LARÊDO, Salomão. Movimentos literários locais. Disponível em: http://slaredo.blogspot.com.br/2012/03/ movimentos-literarios-locais.html. Acesso: 20/05/2012.

15 "Batuque, da autoria de Bruno de Menezes (1893/1963), embora seja um livro de poesia, faz-nos lembrar de uma narrativa iorubá, pois o drama do negro oprimido é denunciado por meio de uma "narratividade poética". (FARES; NUNES, 2010).

${ }^{16}$ Castro (2010) descreve esse processo em Referências Musicais de Bruno Batuque.
}

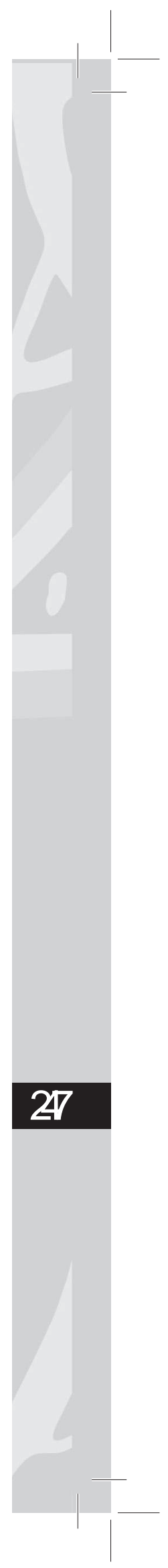




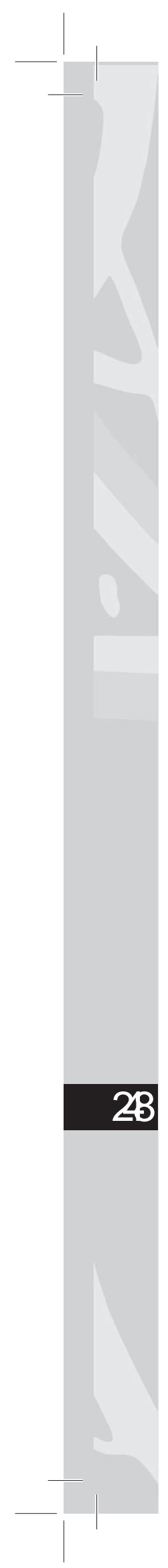

É sabido quantas obras da arte e da literatura, avaliadas como interpretações paradigmáticas de nossa identidade, foram realizadas fora do continente, ou ao menos dos países natais de seus autores. Desde Sarmiento, Alfonso Reyes e Oswald de Andrade até Cortázar, Botero e Glauber Rocha. O lugar do qual vários milhares de artistas latino-americanos escrevem, pintam ou compõem músicas já não é a cidade na qual passaram a infância, nem tampouco é essa na qual vivem há alguns anos, mas um lugar híbrido, no qual se cruzam lugares realmente vividos (CANCLINI, 2008, p. 327).

As guitarradas ${ }^{17}$ são um grande exemplo desse processo na cultura do Pará. Utilizam a guitarra elétrica e os ritmos caribenhos, influência das ondas das rádios como PRC5 (atual rádio Clube do Pará), durante a primeira metade do século passado, e das rádios caribenhas, com ótima recepção na região, em frente às rádios brasileiras do sudeste. O que em termos de processo cultural mostra outro Brasil na área musical. O Brasil do norte, sob influências diferentes. No artigo: Desvendando o Caribe no Pará ${ }^{18}$, o musicólogo Bernardo Farias descreve esse processo singular na história paraense, da influência caribenha na formação da música produzida nesse Estado, tão ícone daquilo que se considera cultura local.

No que tange às mitopoéticas amazônicas, muitas apresentam estrutura semelhante às histórias gregas clássicas. A Iara, a mãe-d'água, e as sereias de Homero e de Camões são extremamente semelhantes. As belíssimas mulheres-peixe, encantadoras de marinheiros, ou pescadores na aculturação local. A cultura mundial está repleta de seres que constitutivamente se assemelham a outros numa cultura

\footnotetext{
${ }^{17}$ Gênero musical originário do Estado do Pará/Brasil.

18 Cf. FARIA, Bernardo. Desvendando o Caribe no Pará. Disponível em: http://www.bregapop.com/servicos/historia/338-bernardo-faria/4956desvendando-o-caribe-no-para-bernardo-faria Acesso em: 18/05/2012.
} 
diversa, mesmo quando queiramos afirmar a sua univocidade ou originalidade.

E o naturalista Inglês de Souza, em seus contos amazônicos, descreve, em Acauã, a famosa Cobra-Grande, que também ronda o imaginário social de Belém, afirmando-se que a cobra (Boiúna) estaria em profunda hibernação, que seria renovada todo ano durante o Círio de Nazaré. O trajeto do círio é o trajeto onde repousa a famosa cobra. Tão semelhante à outra narrativa também brasileira: Boitatá; que, segundo consta, criada/recolhida pelo padre José de Anchieta. Semelhante também à outra narrativa advinda das terras da Escócia: O monstro do lago Ness, descrito como uma grande serpente que repousa em um lago nas terras altas da Escócia. Outras histórias de mesmo cerne são aquelas relacionadas às Anacondas, gigantescas, cobras que vagam pelos rios da região, perpetuadas nos filmes e também presentes no imaginário social de populações da Amazônia de língua espanhola. Os monstros marinhos descritos pelos escritores na expansão marítima europeia, muitos desses apresentados como imensas serpentes, assemelhamse às narrativas orais da Amazônia.

$\mathrm{Na}$ mesma história (Acauã), uma das personagens, Vitória, ao aparecer no casamento da irmã Aninha, assemelha-se à famosa Medusa das histórias mitológicas gregas, a mulher com cabelos de serpente. Situações que comprovam que a hibridação e a influência das narrativas orais da literatura da Amazônia têm raízes em intercâmbio cultural ressignificado.

No campo da estrutura, as histórias se assemelhariam, o que se modificaria então é o seu lugar no processo ideológico de afirmação como cultura de centro e cultura de margem; a via de transmissão, uma oral outra escrita; e a própria utilização da linguagem e de recursos estilísticos diferenciados. Mas, no que tange ao intercâmbio e à comunicação intercultural, não se poderia afirmar um não universalismo.

A literatura da Amazônia como oriunda de um meio extremante híbrido, principalmente quando falamos em termos étnicos, reflete 


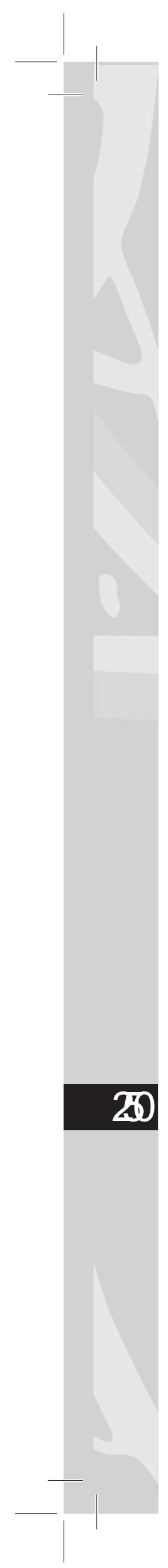

exatamente esse hibridismo em suas produções culturais. Pintar o local não é necessariamente sinônimo de regionalismo, de uma literatura menor; Dalcídio, ao compor suas obras, utiliza-se da linguagem popular da Amazônia como molde para seus dramas sociais e existenciais, comuns em muitos sistemas simbólicos.

\begin{abstract}
Percebe-se que ao narrar os fatos, descrever paisagens, recordar acontecimentos, Dalcídio o faz quase sempre oferecendo-nos um abundante material folclórico, linguístico-lexical e dialectológico, acompanhado de um sem-número de ditos e modismos regionais, que o povo cria e recria, recolhe e armazena na memória coletiva. [...] ele passa a retratar em suas obras-humanas, (dada a verossimilhança com que fora escrita) por meio de uma linguagem simples e pura, viva e pitoresca. Assim, cada passo e cada sofrimento de seu mundus vivendi (representado por pessoas simples, humildes, como pescadores... e muitos doutores que detém o poder, mas não a emoção) aparecem emoldurados em suas páginas. [...] E nesta condição, ao comentar a dramaticidade vivida por essas pessoas, o faz com um realismo que nos envolve e nos coloca no meio deles. [...] Alimentando o seu imaginário, Dalcídio desvenda os segredos do mundo, e possibilita-nos conhecer outra forma de viver - a da pobreza, que ele tanto viveu e sentiu (ASSIS, 1996, p. 42-44).
\end{abstract}

Logo, a literatura de Dalcídio, ao utiliza-se como fonte a linguagem (há objetivo maior da literatura (poesia) do que a renovação da linguagem? Faustino (2003) retifica essa ideia) popular da região como seu amuleto (fonte de poder) para a propagação de uma realidade, não o faz num sentido de observação somente do particular, mas de um universal. Os problemas sociais humanos são desvelados não pela ótica de um narrador observador, como Euclides da Cunha e outros exploradores estrangeiros, e sim de um narrador onisciente, que desvela, por meio do monólogo interior, o modo de pensar sobre o meio, sobre a vida de gente muito pobre, humilde, 
que passa despercebida no mundo caleidoscópico moderno e pósmoderno.

\section{Considerações Finais}

A cultura no singular não existe. O homem não é um ser isolado. Ele vive/convive com outros (a linguagem é um produto social). Por isso, o intercâmbio cultural é constante. Queiramos ou não, sempre haverá mudanças, isso é automático e imanente aos processos simbólicos. O próprio "local" é híbrido, pois é um estágio ao mesmo tempo sincrônico e diacrônico no processo da dialogia cultural. $\mathrm{Na}$ literatura (cultura) da Amazônia, que transita entre uma tradição e uma modernidade, muitos dos processos simbólicos considerados locais são ressignificações de outros processos, pautando-se uma sistemática aculturada que por vezes supera o seu modelo tradicional (imitando, mas não diluindo). E que muitas das obras consideradas regionalistas, não mais são do que fruto de uma sistemática ideológica mantenedora de culturas na margem por questões políticas, não por questões estéticas. Então, acabam-se tachando certos processos simbólicos como locais apenas pela utilização de temáticas, cor local, desconhecendo de fato o seu processo de formação, influências e intercâmbios, propondo uma ótica particularista de homogeneização, não seguindo uma visão estética da busca por uma beleza, mas da imposição de um sistema simbólico etnocêntrico e estéril.

\section{REFERÊNCIAS}

ASSIS, Rosa. Dalcídio Jurandir: a simplicidade de um simples e alguns aspectos de sua obra. Asas da Palavra. v.3, n. 4, junho/96. Belém: Unama, 1996.

BAUDELAIRE, Charles. A exposição Universal de 1855. In: A Modernidade de Baudelaire. Trad. Suely Cassal. Rio de Janeiro: Paz e Terra, 1998. 
BERND, Zilá. Literatura e identidade nacional. $2^{\text {a }}$ ed. Porto Alegre: Editora da UFRGS, 2003.

CALVET, Jean-Louis. Sociolinguística: uma introdução crítica. São Paulo: Parábola, 2002.

CANCLINI, Néstor. Culturas Híbridas: estratégias para entrar e sair da Modernidade. Trad. Heloísa PezzaCintrão, Ana Regina Lessa. $4^{a}$ ed. $4^{a}$ reimpr. São Paulo: Editora da Universidade de São Paulo, 2008.

CASTRO, Urubatan Ferreira de. Referências Musicais de Bruno Batuque. Seminário do Grupo de Pesquisa Culturas e Memórias Amazônicas: Avaliação e Prospecção. JosebelAkel Fares (Org.). Belém: UEPA, 2010.

D’AZEVEDO, João Lúcio. Os jesuítas no Grão-Pará: suas missões e a colonização. Belém: SECULT, 1999.

FARES, Josse. Mergulho ansioso nos campos de Dalcídio ou bebendo água da chuva nas palmas da mão. Asas da Palavra.v.3. N. 4, junho/96. Belém: Unama, 1996.

FARES, Josse; NUNES, Paulo. Amazônia: vozes em negritude. Rio de Janeiro: Mulembarevista científica. n. 2. Rio de Janeiro: UFRJ, 2010.

FARIAS, Bernardo. Desvendando o Caribe no Pará. Disponível: http://www.bregapop.com/servicos/historia/338-bernardofaria/4956-desvendando-o-caribe-no-para-bernardo-faria Acesso: 18/05/2012.

FAUSTINO, Mário. De Anchieta aos Concretos. São Paulo: Companhia das Letras, 2003.

FERNANDES, José Guilherme dos Santos. Literatura Brasileira de Expressão Amazônica, Literatura Amazônica ou Literatura da Amazônia? Revista Moara, n. 23, jan/jun., Belém, 2005. p.178-189. 
KESTLER, I. M. F. O conceito de literatura universal em Goethe. Revista Cult, v. 130, p. 46-49, São Paulo, 2008.

SANTIAGO, Silviano. "Apesar de dependente, universal". In: Vale quanto pesa: ensaios sobre questões político-culturais. Rio de Janeiro: Paz e Terra, 1982.

SOUZA, Roberto Acízelo de. Uma ideia moderna de literatura: textos seminais para os estudos literários (1688-1922). In: SOUZA, Roberto Acízelo (Org.). Chapecó: Argos, 2011.

ZOURABICHVILI, François. O Vocabulário de Deleuze. Trad. André Telles. Rio de Janeiro: Relume-Dumará, 2004. 